\title{
Tamarindus indica L. - A review of traditional uses, phytochemistry and pharmacology
}

\author{
Emmy De Caluwé (1), Kateřina Halamová (2), \\ Patrick Van Damme (1)
}

(I) Department of Plant Production, Ghent University, Belgium

(2) Department of Crop Sciences and Agroforestry in Tropics and Subtropics, Czech University of Life Sciences Prague, Praha, Czech Republic

\begin{abstract}
Tamarind (Tamarindus indica, Fabaceae), a tropical fruit found in Africa and Asia is highly valued for its pulp. Tamarind fruit pulp has a sweet acidic taste due to a combination of high contents of tartaric acid and reducing sugars. The pulp is used for seasoning, in prepared foods, to flavour confections, curries and sauces, and as a major ingredient in juices and other beverages. Commercial tamarind-based drinks are available from many countries. Vitamin B content is quite high; carotene and vitamin $C$ contents are low. Presence of tannins and other dyeing matters in the seed testa make the whole seed unsuitable for consumption, but they become edible after soaking and boiling in water. Tamarind kernel powder is an important sizing material in textile, paper and jute industries. Seeds are gaining importance as an alternative source of proteins, and are besides rich in some essential minerals. Seed pectin can form gels over a wide $\mathrm{pH}$ range. Leaves and flowers can be eaten as vegetables, and are prepared in a variety of dishes. They are used to make curries, salads, stews and soups. Tamarind leaves are a fair source of vitamin $\mathrm{C}$ and $\alpha$-carotene; mineral content is high, particularly P, K, Ca and Mg. Anti-oxidant, anti-inflammatory, anti-microbial and anti-fungal activity has been documented from several plant parts. Tamarind is also extensively used in traditional medicine. The traditional uses, its phytochemistry and pharmacognosy is reviewed to provided with a particular orientation to its value in sub-Sahara Africa.
\end{abstract}

Key words: Tamarind, Tamarindus indica L., traditional use, phytochemistry, pharmacology, amino acids, fatty acids, minerals, vitamins, anti-nutritional factors

\section{Introduction}

Tamarind or Tamarindus indica L. of the Fabaceae, subfamily Caesalpinioideae, is an important food in the tropics. It is a multipurpose tree of which almost every part finds at least some use (Kumar \& Bhattacharya, 2008), either nutritional or medicinal. Tamarind is indigenous to tropical Africa but it has been introduced and naturalized worldwide in over 50 countries. The major production areas are in the Asian countries India and Thailand, but also in Bangladesh, Sri Lanka, Thailand and Indonesia. In America, Mexico and Costa Rica are the biggest producers. Africa on the whole does not produce tamarind on a commercial scale, though it is widely used by the local people. Minor producing countries in Africa are Senegal, Gambia, Kenya, Tanzania and Zambia (El-Siddig et al., 2006). 


\section{Objectives and Methodology}

Many authors have published about the multipurpose tamarind tree. Nevertheless, only a few of these authors have presented a (general) literature review, and none of these dealt simply and solely with the nutritional and medicinal value of tamarind products. For that reason, we decided to collect, document and compare detailed data on traditional uses, phytochemistry and pharmacology for fruit pulp, seeds, leaves and flowers, and bark of the tamarind tree.

The literature search was done by using the following search terms: 'tamarind' and 'Tamarindus indica'. The authors included, without time limitation, all available information as proposed on Web of Science, consisting of different databases containing information gathered from thousands of scholarly journals, books, book series, reports and conferences. As is conventional in ethnobotanical reviews, authors respected original definitions, descriptions and/or naming of diseases and afflictions. However, we are fully aware that this leaves sometimes doubt on the exact nature (i.e. disease names as known in formal western medicine) but consider the latter equations to be outside of the scope of this article.

During our literature review, a large variation in information and data was encountered and the reported values were, as much as possible, converted into the same unit. Authors are thus aware that there might be discrepancies in analytical data presented in some tables (e.g. Table V and Table X). It should be understood however, that each laboratory or research group uses specific analytical tools and that it is impossible to streamline results in such a way that they could be compared using the same standard. The reader is referred to the original articles for details about analytical methods and correct interpretation of the results obtained.

\section{Food Uses}

Fruits

Tamarind fruit pulp is used for seasoning, as a food component, to flavour confections, curries and sauces, and is a main component in juices and certain beverages. Tamarind fruit pulp is eaten fresh and often made into a juice, infusion or brine (El-Siddig et al., I999; El-Siddig et al., 2006), and can also be processed into jam and sweets (Figure I). The refreshing drinks are popular in many countries around the world, though there are many different recipes. In some African countries, the juice obtained from the fruit pulp is mixed with wood ash to neutralize the sour taste of the tartaric acid. However, the most common method is to add sugar to make a pleasantly acid drink. In Ghana, the pulp is mixed with sugar and honey to make a sweet drink. Most of the producing countries manufacture drinks commercially. Sometimes pulp is fermented into an alcoholic beverage (FAO (1988) cited in El-Siddig et al., 2006).

\section{Seeds}

Tamarind seed is a by-product of the tamarind pulp industry. The presence of tannins and other dyeing matter in the testa make the whole seed unsuitable for direct con- 
sumption (Rao \& Srivastava (1974) cited in Kumar \& Bhattacharya, 2008). However, the seeds become edible after soaking and boiling in water, which removes the seed coat (ElSiddig et al., 2006). In the past, and even today, seeds have been wasted (El-Siddig et al., 2006) even though they could be ground to make a palatable livestock feed (NAS (I979) cited in El-Siddig et al., 2006). The major industrial product of tamarind seed is the tamarind kernel powder (TKP) which is an important sizing material used in the textile, paper, and jute industries (Kumar \& Bhattacharya, 2008). Tamarind seed is also the raw material used in the manufacture of polysaccharide (jellose), adhesive and tannin. In 1942, two Indian scientists announced that decorticated kernels contained $46-48 \%$ of a gel-forming substance. This polysaccharide (pectin) with carbohydrate character and gelly forming properties, named 'jellose' (Rao (1948 and 1956) cited in El-Siddig et al., 2006), has been recommended for use as a stabiliser in ice cream, mayonnaise and cheese, and as an ingredient or agent in a number of pharmaceutical products (Morton, 1987; El-Siddig et al., 2006). Flour from the seed may be made into cake and bread. Roasted seeds are claimed to be superior to groundnuts in flavour (ICRAF, 2007).

In view of the overall nutrient and chemical composition, tamarind seeds may be adopted as an inexpensive alternative protein source to alleviate protein malnutrition among traditional people living in developing countries (Siddhuraju et al., I995).

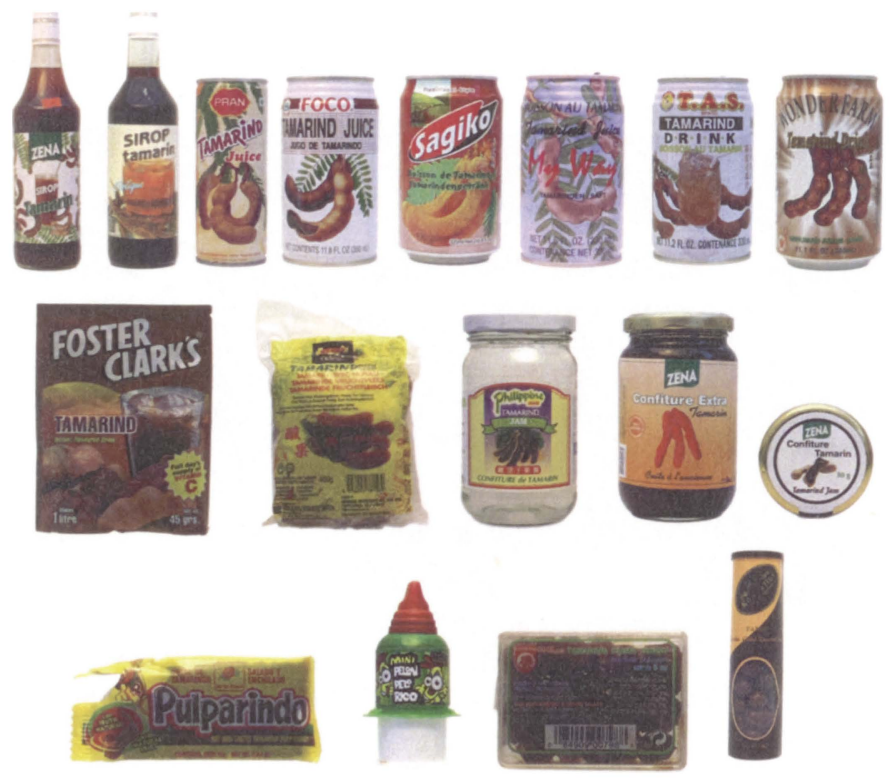

Figure 1. Above and from left to right: two different kinds of tamarind syrup and six different kinds of tamarind juices; Middle and from left to right: instant flavoured tamarind drink, tamarind fruit pulp to be used in different recipes and two different kinds of tamarind jam; Under: four different kinds of tamarind sweets (Source: Emmy De Caluwe). 


\section{Leaves and Flowers}

Tamarind leaves and flowers can be eaten as vegetables and are prepared in a variety of dishes (ICRAF, 2007). They are used to make curries, salads, stews and soups in many countries, especially in times of scarcity (Benthall (1933) cited in El-Siddig et al., 2006). Before consumption, leaves are sometimes boiled in water and prepared as tamarind fruits (Nordeide et al., I996).

\section{Phytochemistry}

The chemical composition of amino acids, fatty acids, and minerals of tamarind plant parts have been reported. Differences in values found in the literature are likely to be due to differences in genetic strains, stages of maturity at which the plant parts were harvested, growing conditions (Glew et al., 2005), harvesting and handling techniques as well as to differences in analytical methodologies. Nevertheless, a review of the phytochemistry will provide insight into the relative value that this species provides when used.

\section{Fruits}

Nutritional composition of tamarind fruit (Figure 2) varies considerably (Morton, 1987; Chapman (1984) and Persueglove (1982) both cited in El-Siddig et al., 1999). However, a typical fruit contains $40 \%$ pulp (El-Siddig et al., 1999). According to other authors, the fruit contains about $55 \%$ pulp, $34 \%$ seeds, and $11 \%$ shell (pod) and fibres (Rao \& Srivastava (1974) cited in Kumar \& Bhattacharya, 2008).
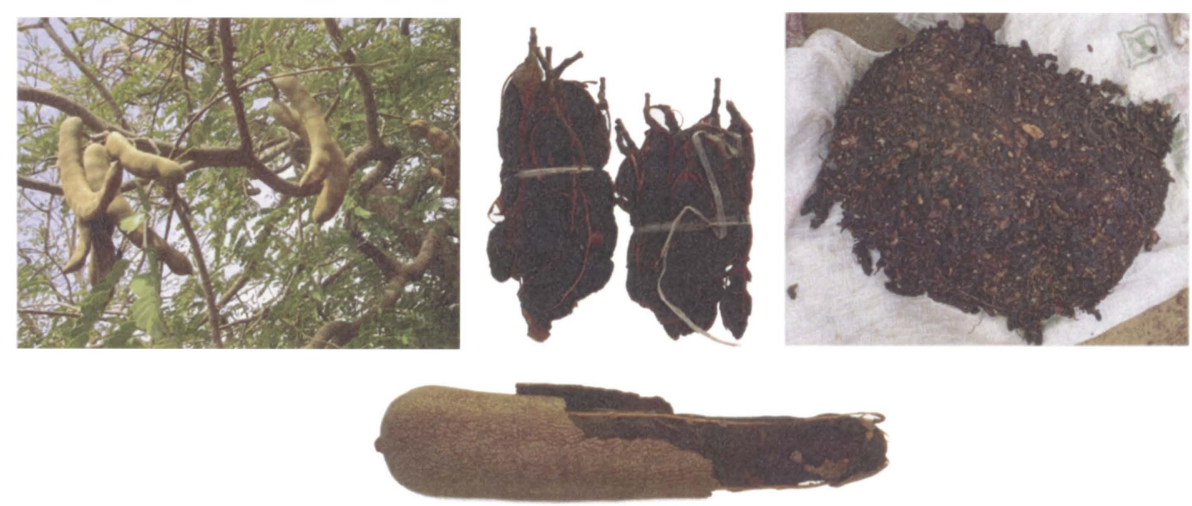

Figure 2. Above and from left to right: fresh and dried tamarind fruits (Source: Emmy De Caluwé, Senegal, 2007), dried tamarind fruits sold at market (Source: Camille De Moor, Mali, 2007); Below: close-up of tamarind fruit (Source: Emmy De Caluwe).

Pods contain I-Io seeds, which are irregularly shaped, flattened or rhomboid. Seeds are very hard, shiny, reddish, or purplish brown. They are embedded in the pulp, lined with a tough parchment resembling a membrane, and joined to each other with tough fibres (Purseglove (1987) cited in Kumar \& Bhattacharya, 2008). There are great differences and variations in fruit size and flavour (Kumar \& Bhattacharya, 2008). 


\section{Fruit Pulp}

Tamarind is valued highly for its fruits, especially the pulp which is used for a wide variety of domestic and industrial purposes (Kulkarni et al. (1993) cited in El-Siddig et al., 2006), especially for food and beverages (Ajayi et al., 2006). The pulp constitutes 30-50\% of the ripe fruit (Purseglove (1987) and Shankaracharya (1998) both cited in El-Siddig et al., 2006), the shell and fibre account for II-30\% and the seed about 25-40\% (Chapman (I984) and Shankaracharya (1998) both cited in El-Siddig et al., 2006). The most outstanding characteristic of tamarind is its sweet acidic taste, the acid due to mostly tartaric acid (10\%) (El-Siddig et al., 1999). The latter is synthesised in tamarind leaves in the light and translocated to the flowers and fruits (Lewis et al. (I96I) and Patnaik (1974) both cited in El-Siddig et al., 2006). Tartaric is an unusual plant acid formed from the primary carbohydrate products of photosynthesis, and once formed, it is not metabolically used by the plant (El-Siddig et al., 2006). The content of tartaric acid does not decrease during fruit ripening, suggesting it is not utilized in fruit development. At this same time of fruit development; reducing sugars increase to $30-40 \%$ giving the sour fruit a sweeter taste (El-Siddig et al., 2006). As a result, tamarind is known to be simultaneously the most acidic and sweetest fruit (Lewi \& Neelakantan (I964a) and Coronel (I99I) both cited in El-Siddig et al., 2006). In Thailand, two species of tamarind occur, the so-called sweet and sour tamarind (Figure 3 ). Besides being a rich source of sugars, tamarind fruit is an excellent source of vitamin B (Ajayi et al., 2006) and also contain minerals and exhibit high antioxidant capacity that appear to be associated with a high phenolic content, thus can be an important food source (El-Siddig et al., 2006).

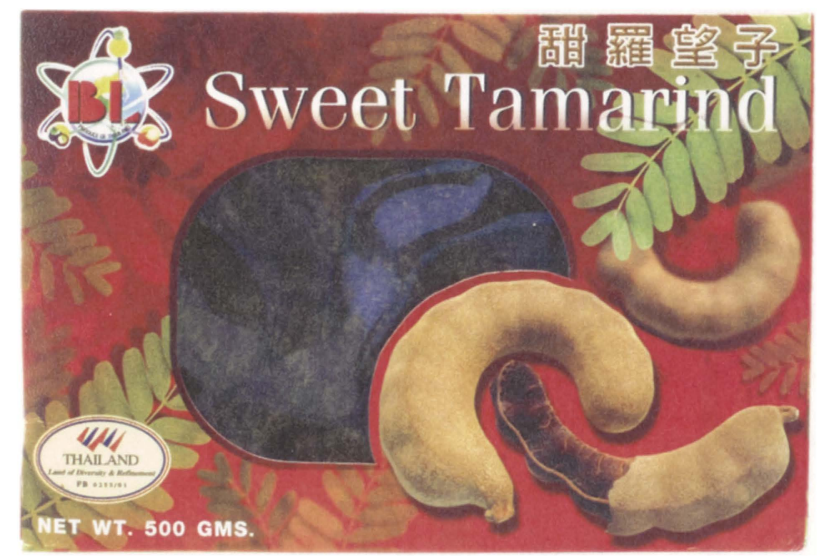

Figure 3. Sweet tamarind (Source: Emmy De Caluwe). 


\section{Chemical Composition}

Tamarind pulp typically contains $20.6 \%$ water, $3.1 \%$ protein, $0.4 \%$ fat, $70.8 \%$ carbohydrates, 3.0\% fibre and 2.I\% ash (El-Siddig et al., I999), thus the pulp has a low water content and a high level of protein, carbohydrates and minerals. Nevertheless, the proximate composition of the tamarind fruit depends on locality (El-Siddig et al., 2006). Table I shows the chemical composition of tamarind pulp. 


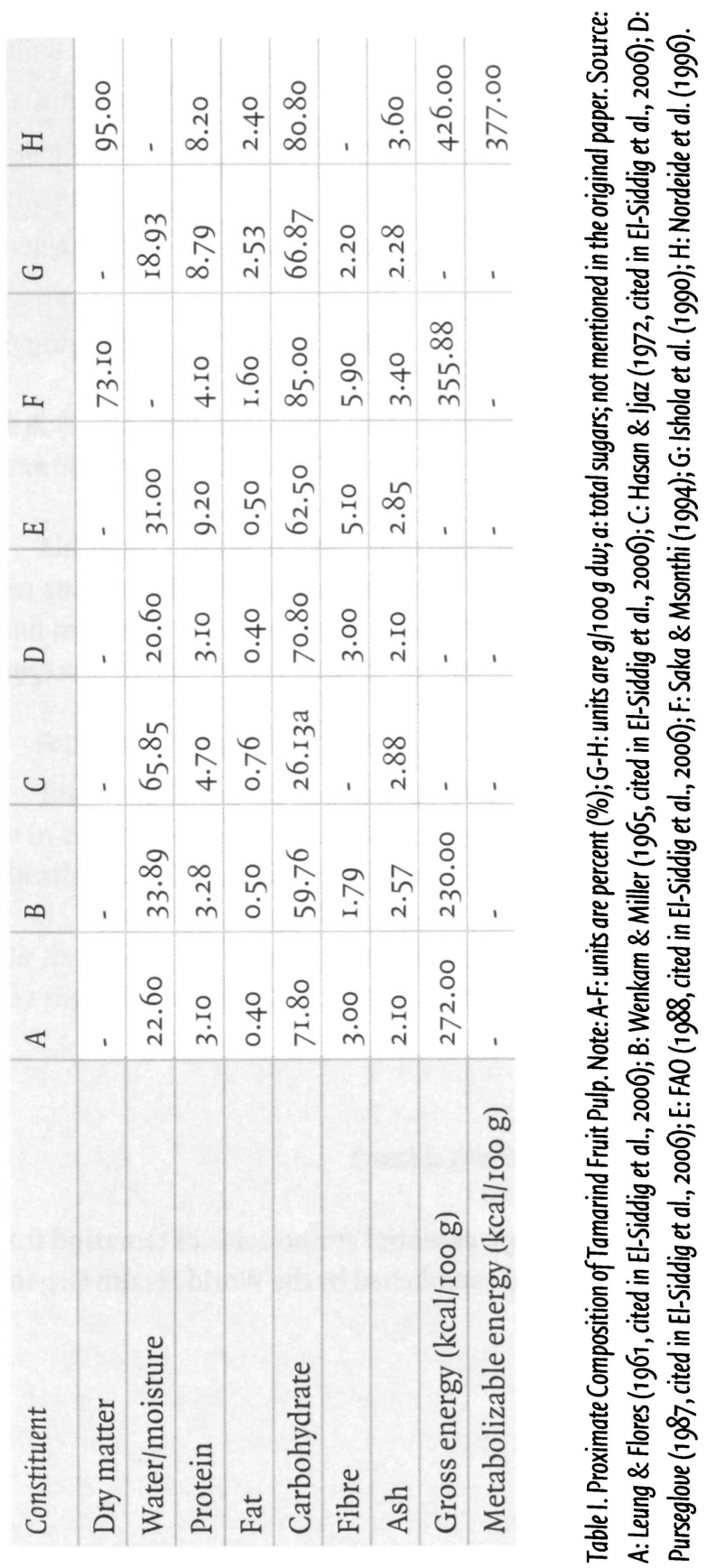




\section{Amino Acid Profile}

The fruit pulp is relatively poor in protein though the fruit is rich in several amino acids (Ishola et al., I990). Glew and co-workers reported the amino acid composition of tamarind fruit pulp (Table II).

\begin{tabular}{l|l|l}
\multicolumn{2}{l|l}{ Amino Acid } & \multicolumn{1}{l}{ mglg dw } \\
\hline \multicolumn{2}{l}{ Crude protein (Total protein) } & II6.00 \\
\hline Aspartic acid & ASP & I 2.00 \\
\hline Glutamic acid & GLU & I6.70 \\
\hline Serine & SER & 6.88 \\
\hline Glycine & GLY & 5.15 \\
\hline Histidine & HIS & 3.37 \\
\hline Arginine & ARG & 8.74 \\
\hline Threonine & THR & 6.05 \\
\hline Alanine & ALA & 6.20 \\
\hline Proline & PRO & $7.6 \mathrm{I}$ \\
\hline Tyrosine & TYR & 4.34 \\
\hline Valine & VAL & 6.97 \\
\hline Methionine & MET & 2.48 \\
\hline Isoleucine & ILE & 5.20 \\
\hline Leucine & LEU & 8.89 \\
\hline Phenylalanine & PHE & 4.78 \\
\hline Lysine & LYS & 8.22 \\
\hline Cysteine & CYS & I.35 \\
\hline Tryptophan & TRP & I.04 \\
\hline
\end{tabular}

Table II. Amino Acid Composition of Tamarind Fruit Pulp. Source: Glew et al. (2005).

According to the same authors (Glew et al., 2005), essential amino acids of tamarind fruit pulp exceed those of the 'ideal' protein standard established by the World Health Organization, except for tryptophan $(82 \%)$ (Table III). 


\begin{tabular}{l|l} 
Amino Acid & Tamarind Fruit/Ideal $\times 100 \%$ \\
\hline Threonine & I53 \\
\hline Valine & I72 \\
\hline Methionine + cystine & I32 \\
\hline Isoleucine & I60 \\
\hline Leucine & II5 \\
\hline Phenylalanine + tyrosine & I25 \\
\hline Lysine & I23 \\
\hline Tryptophan & 82
\end{tabular}

Table III. Essential Amino Acid Content of Tamarind Fruit Pulp Compared to WHO's 'Ideal' Standard. Source: Glew et al. (2005).

Although tamarind fruit contains potentially useful amounts of protein, they have been shown to be poorly digested and utilized by rats, as compared with proteins in coconut meat that are extensively digested and efficiently utilized by mammals (Grant et al. (1995) and Mepba et al. (2003) both cited in Glew et al., 2005).

\section{Fatty Acid Profile}

Tamarind fruit pulp is relatively poor in oil ( $25.3 \mathrm{~g} / \mathrm{kg}$ of crude lipid), greenish yellow in colour and liquid at room temperature. Saponification values of the oil are high, indicating that it contains a high proportion of low molecular weight fatty acids (Ishola et al., 1990). With regard to the two essential fatty acids, the fruit pulp contains very little linoleic acid ( $3.42 \mathrm{mg} / \mathrm{g}$ dry weight) and even lower amounts of $\alpha$-linolenic acid (0.21 mg/g dry weight) (Glew et al., 2005) (Table IV). 


\begin{tabular}{l|l} 
Fatty Acid & $\mu g / g d w$ \\
\hline Cr2:0 & 0.01 \\
\hline Cr4:0 Myristic & 0.01 \\
\hline Cr5:0 & 0.01 \\
\hline Cr6:0 Palmitic & I.80 \\
\hline Cr6:In-7 Palmitoleic & 0.12 \\
\hline Cr8:0 Stearic & 0.70 \\
\hline Cr8:In-9 Oleic & 2.29 \\
\hline Cr8:In-7 & 0.55 \\
\hline Cr8:2n-6 Linoleic & 3.42 \\
\hline Cr8:3n-3 $\alpha$-linolenic & 0.21 \\
\hline C20:0 Arachidic & 0.07 \\
\hline C20:I Gadoleic & 0.02 \\
\hline C20:2n-6 & 0.01 \\
\hline C22:0 & 0.03 \\
\hline C22:I & 0.01 \\
\hline C24:0 & 0.03 \\
\hline C24:I & 0.20 \\
\hline Total lipid content (mg/g dw) & 9.40 \\
\hline
\end{tabular}

Table IV. Fatty Acid Content of Tamarind Fruit Pulp. Source: A: Glew et al. (2005).

\section{Mineral Composition}

The fruit pulp is a rich source of several macro and micro elements (Table V), including relatively high amounts of copper, manganese and zinc. Fruit pulp is also a good source of calcium and phosphorus (El-Siddig et al., 1999), but is unfortunately, extraordinarily low in iron (Glew et al., 2005). Almeida et al. (2009) indicated that tamarind is a rich source of all minerals available, especially magnesium, copper and potassium, in addition to being a good source of calcium, phosphorous, iron and selenium. The consumption of Ioo $\mathrm{g}$ tamarind fruit pulp by an adult will cover $10.69 \%$ of the recommended daily intake of calcium, $20.49 \%$ of magnesium, $14.21 \%$ of phosphorous, $12.07 \%$ of iron, $2.61 \%$ of manganese, $1.29 \%$ of zinc, $32.22 \%$ of copper and $9.21 \%$ of selenium, respectively (Almeida et al., 2009).

Tuntipopipat et al. (2009) investigated the inhibitory effects for spices and herbs, including tamarind, on iron availability. Tamarind is rich in polyphenolic compounds that are expected to inhibit iron absorption by forming iron complexes in the intestine, making dietary iron less available for absorption. The authors found that all tested spices and herbs showed a dose-dependent reduction of relative iron availability in a rice based meal, with the exception of tamarind. Addition of tamarind containing I mg polyphenol 
to the reference meal increased the relative dialyzable iron. This may be explained by the antagonistic effect of tartaric acid over the inhibitory effect of phenolic compounds in tamarind.

\section{Vitamins}

The ascorbic acid content in tamarind is very low and varies from $2-20 \mathrm{mg} / \mathrm{roog}$ (Lefevre (I97I) and Ishola et al. (1990) both cited in El-Siddig et al., 2006). Tamarind fruit pulp was reported to have a high content of vitamin B (thiamine, riboflavin and niacin) as well as a small amounts of carotene and vitamin C (El-Siddig et al., I999; ICRAF, 2007).

\begin{tabular}{|c|c|c|c|c|c|c|c|}
\hline Minerals & & A & B & C & D & E & $\mathrm{F}$ \\
\hline $\mathrm{Al}$ & Aluminium & - & - & - & I. 84 & - & - \\
\hline $\mathrm{Ba}$ & Barium & - & - & - & 0.20 & - & - \\
\hline $\mathrm{Ca}$ & Calcium & $465 \cdot 75$ & I7.10 & 240.00 & o.19 & 74.00 & Io6.88 \\
\hline $\mathrm{Cu}$ & Copper & 21.83 & - & - & 0.91 & 0.09 & 0.29 \\
\hline Co & Cobalt & - & - & - & 0.01 & - & 0.05 \\
\hline $\mathrm{Cr}$ & Chromium & - & - & - & 0.29 & - & - \\
\hline $\mathrm{Fe}$ & Iron & 8.49 & 6.80 & I4.00 & 3.17 & 2.80 & I.69 \\
\hline $\mathrm{K}$ & Potassium & 62.00 & 1226.90 & - & 0.65 & 628.00 & 790.II \\
\hline $\mathrm{Mg}$ & Magnesium & 72.03 & I28.20 & - & 0.12 & 92.00 & 53.28 \\
\hline $\mathrm{Mn}$ & Manganese & - & - & - & 21.50 & - & 0.06 \\
\hline Mo & Molybdenum & - & - & - & 0.01 & - & - \\
\hline $\mathrm{Na}$ & Sodium & 76.66 & II.IO & - & 6.21 & 28.00 & 13.95 \\
\hline $\mathrm{Ni}$ & Nickel & 0.52 & - & - & 0.13 & - & 0.08 \\
\hline $\mathrm{P}$ & Phosphorus & 91.00 & Io8.10 & - & 0.12 & II 3.00 & 99.49 \\
\hline $\mathrm{Pb}$ & Lead & - & - & - & 0.01 & - & - \\
\hline St & Strontium & - & - & - & 0.28 & - & - \\
\hline $\mathrm{Ti}$ & Titanium & - & - & - & 0.02 & - & - \\
\hline $\mathrm{Zn}$ & Zinc & I.o6 & - & 2.30 & I. 32 & O.10 & 0.09 \\
\hline
\end{tabular}

Table V. Mineral Content of Tamarind Fruit Pulp. Note: units are mg/100 $\mathrm{g} \mathrm{dw} ;-:$ not mentioned in the original paper. Source: A: Ishola et al. (1990); B: Saka \& Msonthi (1994); C: Nordeide et al. (1990); D: Glew et al. (2005); E: USDA (2007, cited in Almeida et al., 2009); F: Almeida et al. (2009).

\section{Seeds}

Tamarind seed consists of the seed coat or testa (20-30\%) and the kernel or endosperm (70-75\%) (Coronel (199I) and Shankaracharya (1998) both cited in El-Siddig et al., 2006). Tamarind seed is a typical underutilized material (Kumar \& Bhattacharya, 2008). Locally, the seeds are used as soup thickener (Ajayi et al., 2006). Commercially, 
tamarind seed is a by-product of the commercial utilization of the fruit pulp; and has been reported to have several uses (El-Siddig et al., 2006; Kumar \& Bhattacharya, 2008). Tamarind seeds can be used for extracting tamarind gum, whereas the seed coats, a byproduct of manufacturing tamarind gum, were found as a source of natural antioxidants (Tsuda et al., 2004). The seeds are presently gaining importance as an alternative source of proteins (El-Siddig et al., 2006).

\section{Pectin}

As described above, tamarind seed kernels contain polysaccharides, when mixed with water form mucilaginous dispersions and possess the property of forming gels with sugar concentrates, like fruit pectins. However, unlike other fruit pectins, tamarind polysaccharide can form gels over a wide $\mathrm{pH}$ range, including neutral and basic conditions. Tamarind polysaccharides, contrary to fruit pectins, are not affected by boiling in neutral aqueous solutions, even if boiled for long periods. Therefore, it can be useful as a gel formation agent and substituted for fruit pectins. Tamarind polysaccharides do not contain galacturonic acid and methyluronate, and is therefore not regarded as a true pectin, being termed as 'jellose' (Rao (1948) cited in El-Siddig et al., 2006).

\section{Chemical Composition}

Tamarind seeds are rich sources of different components (Ishola et al., 1990; Siddhuraju et al., I995; Ajayi et al., 2006) (Table VI). In general, the seeds are good sources of protein, crude fibre and carbohydrate. The mineral concentrations are high, especially those of potassium and magnesium (Ajayi et al., 2006). The seed and kernels are high in proteins $(13-20 \%)$, while the seed coat is rich in fibre (20\%) and tannins (20\%) (El-Siddig et al., 2006). The protein content concentration of tamarind seeds can contribute to the daily protein need of $23.6 \mathrm{~g} / \mathrm{loo} \mathrm{g}$ for adults as recommended by the National Research Council (1974, cited in Ajayi et al., 2006). Moreover, the fairly high crude fibre content is of nutritional significance since fibre helps to maintain the health of the gastro-intestinal tract (Ajayi et al., 2006). The high saponification value (22I mg KOH/g oil) of tamarind oil indicates the presence of many fatty acids of lower molecular weight, making possible the utilisation of the oil in the manufacture of soaps and lather shaving creams (Ajayi et al., 2006). 


\begin{tabular}{l|l|l|l|l} 
Constituent & A & B & C & D \\
\hline Moisture & I0.10 & 8.00 & - & I0.75 \\
\hline Dry matter & - & - & 8.80 & - \\
\hline Crude protein & 26.93 & I3.00a & I8.3I & $24.28 \mathrm{a}$ \\
\hline Fat/crude lipid & I0.9I & 7.10 & 3.03 & - \\
\hline Ash & $2.0 \mathrm{I}$ & 4.20 & 2.58 & $\mathrm{I.50}$ \\
\hline Crude fibre & 7.40 & 14.00 & $\mathrm{I} 6.73$ & $\mathrm{I} 8.00$ \\
\hline Carbohydrate & 50.05 & $6 \mathrm{I} .70$ & 59.35 & 38.27 \\
\hline Oil yield & - & - & - & 7.20 \\
\hline Metabolizable energy (kJ/loo g) & - & 1520.00 & - & -
\end{tabular}

Table VI. Proximate Composition of Tamarind Seeds. NOTE: units are $\mathrm{g} / 100 \mathrm{~g} \mathrm{dw} ; \mathrm{a}: \% \mathrm{~N} \times 6.25 ;-:$ not mentioned in the original paper. Source: A: Ishola et al. (1990); B: Siddhuraju et al. (1995); C: Lockett et al. (2000); D: Ajayi et al. (2000).

\section{Amino Acid Profile}

According to Ishola and collaborators (1990), tamarind seeds are a good source of protein. Amino acid profiles of tamarind reveal that the proteins contain fairly balanced essential amino acid levels (Table VII). In terms of protein content and WHO standards, tamarind seeds score well for 3 of the 8 essential amino acids. However, for each of the eight essential amino acid categories baobab leaves score close to or above the 100\% mark, except from tryptophan. (Table VIII). Tamarind seeds could, therefore, be used as a less expensive source of protein to help alleviate protein malnutrition found so widespread in many developing countries (Siddhuraju et al. (1995) cited in El-Siddig et al., 2006). 


\begin{tabular}{l|l|l|l} 
Amino Acid & & A & B \\
\hline $\begin{array}{l}\text { Total protein } \\
\text { Aspartic acid }\end{array}$ & ASP & 7.20 & I7.30 \\
\hline Glutamic acid & GLU & I.09 & I.80 \\
\hline Serine & SER & 0.34 & 0.95 \\
\hline Glycine & GLY & 0.44 & I.67 \\
\hline Histidine & HIS & 0.23 & 0.55 \\
\hline Arginine & ARG & 0.44 & I.66 \\
\hline Threonine & THR & 0.20 & 0.52 \\
\hline Alanine & ALA & $0.3 \mathrm{I}$ & 0.65 \\
\hline Proline & PRO & ND & 0.85 \\
\hline Tyrosine & TYR & 0.22 & 0.95 \\
\hline Valine & VAL & 0.45 & $0.7 \mathrm{I}$ \\
\hline Methionine & MET & 0.13 & 0.14 \\
\hline Isoleucine & ILE & 0.33 & 0.67 \\
\hline Leucine & LEU & 0.66 & I.09 \\
\hline Phenylalanine & PHE & 0.34 & $0.7 \mathrm{I}$ \\
\hline Lysine & LYS & 0.48 & I.05 \\
\hline Cysteic acid & CYS & 0.15 & 0.35 \\
\hline Tryptophan & TRP & 0.06 & 0.18 \\
\hline & & &
\end{tabular}

Table VII. Amino Acid Composition of Tamarind Seed. Note: units are g/100 g dw; ND: not detected.

Source: A: Siddhuraju et al. (1995); B: Glew et al. (1997).

\begin{tabular}{l|l} 
Amino Acid & Tamarind Seed/Ideal $\times 100 \%$ \\
\hline Threonine & 75.00 \\
\hline Valine & 82.00 \\
\hline Methionine+ cystine & I40.00 \\
\hline Isoleucine & 97.50 \\
\hline Leucine & 90.00 \\
\hline Phenylalanine + tyrosine & I60.00 \\
\hline Lysine & II0.9I \\
\hline Tryptophan & 25.00
\end{tabular}

Table VIII. Essential Amino Acid Content of Tamarind Seeds Compared to WHO's 'Ideal' Standard. Source: Glew et al. (1997). 


\section{Fatty Acid Profile}

According to Ishola et al. (I990), the seed is a good source of fatty acids (Table IX). Tamarind seeds contained between I and $2 \mathrm{mg} / \mathrm{g}$ dry weight linoleic acid (Glew et al., 1997). Tamarind seeds have a higher percentage of unsaturated ( $55,6 \%)$ fatty acids than saturated (44.4\%) fatty acids (Ajayi et al., 2006). Linoleic acid, present in tamarind seed oil, is undoubtedly one of the most important polyunsaturated acids in human food because of its association in the reduction or prevention of heart vascular diseases (Omode et al. (1995) cited in Ajayi et al., 2006). Dietary fat rich in linoleic acid is, apart from preventing cardiovascular disorders such as coronary heart diseases and atherosclerosis, also associated with preventing high blood pressure (Vles \& Gottenbos (I989) cited in Ajayi et al., 2006). The presence of one of the three essential fatty acids in seed oil makes it nutritionally valuable. Palmitic, stearic and linoleic acids are present in high proportions in tamarind oil, which make the latter nutritionally valuable (Ajayi et al., 2006).

Tamarind seeds give an amber-colored oil, free of smell and sweet in taste, which resembles linseed oil. It is used for varnishes, paints and as burning lamp oil (Morton, I987; El-Siddig et al., 2006), but it is also said to be palatable and of culinary quality (Watt (1893) cited in El-Siddig et al., 2006). Tamarind oil has iodine value below $100 \mathrm{mg} / \mathrm{roo} \mathrm{g}$ which places it in the non-drying oil group (Ajayi et al., 2006). A report by Ekpa \& Ekpe (I995, cited in Ajayi et al., 2006) has shown that, unlike free fatty acid content, which is a measure of free fatty acids present in a fat or oil, acid value is a measure of total acidity of the lipid, involving contributions from all the constituent fatty acids that make up the glyceride molecule. The nutritional value of a fat depends, in some respect, on the amount of free fatty acids. In the tropics, where vegetable oils are the most common dietary lipids, it has been shown that it is desirable that the free fatty acid content of cooking oil lies within $0.0-3.0 \%$ (Bassir (I971) and Onyeike \& Acheru (2002) both cited in Ajayi et al., 2006). The low levels of percent of free fatty acids in tamarind oil indicates that the oil may be a good edible oil with an extended shelf-life without spoilage via oxidative rancidity (Ajayi et al., 2006). 


\begin{tabular}{l|l|l|l} 
Fatty Acid & A & B & C \\
\hline Total fatty acid content $(\mathrm{mg} / \mathrm{g} \mathrm{dw})$ & - & - & 75.00 \\
\hline Cr4:0 Myristic & - & - & $\mathrm{Tr}$ \\
\hline Cr6:o Palmitic & I5.20 & $27.4 \mathrm{I}$ & 0.54 \\
\hline Cr6:I Palmitoleic & - & - & $\mathrm{ND}$ \\
\hline Cr8:o Stearic & 4.19 & $\mathrm{I} 3.86$ & 0.17 \\
\hline Cr8:I Oleic & 24.50 & 24.13 & I.07 \\
\hline Cr8:2 Linoleic & 48.30 & 24.75 & I.65 \\
\hline Cr8:3 Linolenic & 2.50 & - & 0.01 \\
\hline C20:0 Arachidic & - & 2.25 & 0.06 \\
\hline C20:I Gadoleic & - & 3.13 & - \\
\hline C22:0 Behenic & 5.20 & 0.39 & - \\
\hline Total lipid content (\%) & 75.00 & - & -
\end{tabular}

Table IX. Fatty Acid Content of Tamarind Seeds. Note: A-B: units are percent (\%); C: units are mg/g dw; ND: not detected; Tr: trace; -: not mentioned in the original paper. Source: A: Siddhuraju et al. (1995); B: Ajayi et al. (2000); C: Glew et al. (1997).

\section{Mineral Composition}

Tamarind seeds appear to be a good source of different mineral elements (Ishola et al., I990; Siddhuraju et al., 1995; Glew et al., I997; Ajayi et al., 2006), such as calcium, phosphorus, magnesium and potassium (El-Siddig et al., 2006) (Table X). Calcium content of tamarind seeds is quite high compared to that of some of the cultivated pulse crops (Kuzayli et al. (1966) cited in Siddhuraju et al., 1995). Of all the minerals studied in Siddhuraju et al. (1995), $\mathrm{K}$ is the element in highest concentration, with the values for the trace mineral copper also relatively high (Glew et al., 1997). The high concentration of potassium is nutritionally significant considering the fact that potassium plays a principal role in neuro-muscular function (Ajayi et al., 2006). 


\begin{tabular}{|c|c|c|c|c|c|c|c|}
\hline \multicolumn{2}{|c|}{ Minerals } & \multirow{2}{*}{$\begin{array}{l}\text { A } \\
786.86\end{array}$} & \multirow{2}{*}{$\begin{array}{l}\text { B } \\
172.00\end{array}$} & \multirow{2}{*}{$\begin{array}{l}C \\
-\end{array}$} & \multirow{2}{*}{$\begin{array}{l}\text { D } \\
185.00\end{array}$} & \multirow{2}{*}{$\begin{array}{l}E \\
I 42.00\end{array}$} & \multirow{2}{*}{\begin{tabular}{|l} 
\\
36.60
\end{tabular}} \\
\hline $\mathrm{Ca}$ & Calcium & & & & & & \\
\hline $\mathrm{Cu}$ & Copper & I8.97 & 0.47 & 0.73 & I.I 6 & 0.26 & 2.10 \\
\hline $\mathrm{Fe}$ & Iron & ND & 6.30 & 13.70 & 2.67 & 9.09 & $45 \cdot 50$ \\
\hline $\mathrm{K}$ & Potassium & 610.00 & 1340.00 & - & - & - & 1308.00 \\
\hline $\mathrm{Mg}$ & Magnesium & II 8.33 & 214.00 & 28.20 & 196.00 & 201.00 & 104.00 \\
\hline $\mathrm{Mn}$ & Manganese & - & 0.68 & 0.15 & ND & 0.70 & I2.10 \\
\hline Mo & Molybdenum & - & - & - & I. 39 & - & - \\
\hline $\mathrm{Na}$ & Sodium & 19.17 & 21.30 & - & ND & - & 8.90 \\
\hline $\mathrm{Ni}$ & Nickel & ND & - & - & - & - & - \\
\hline $\mathrm{P}$ & Phosphorus & 165.00 & 312.00 & - & 228.00 & 220.00 & - \\
\hline $\mathrm{Zn}$ & Zinc & 3.00 & $7 . \mathrm{IOC}$ & I.22 & 2.63 & 3.12 & 7.00 \\
\hline
\end{tabular}

TableX. Mineral Content of Tamarind Seeds. Note: units are mg/100 g dw; ND: not detected; -: not mentioned in the original paper. Source: A: Ishola et al. (1990); B: Siddhuraju et al. (1995); C: Smith et al. (1990); D: Glew et al. (1997);

E: Lockett et al. (2000); F: Ajayi et al. (2006).

\section{Anti-nutritional Factors}

Tamarind seeds also contain small amounts of anti-nutritional factors such as tannins, phytic acid, hydrogen cyanide, trypsin inhibitor activity and phytohaemaglutination activity (El-Siddig et al., 2006). The presence of tannins and other colouring matter in the testa make the whole seeds unsuitable for direct human consumption. Therefore, the testa has to be separated from the kernels by boiling or roasting. Otherwise, side effects such as depression, constipation and gastro-intestinal disorders may result (Anon (1976) cited in El-Siddig et al., 2006). Bhatta et al. (200I, cited in El-Siddig et al., 2006), have considered that a natural source of tannin from tamarind seed husks can be used to depress gas production in rumen fermentation, particularly in crossbred dairy cows.

Even though food legumes are important sources of dietary protein in developing countries, their acceptability and utilization has been limited due to the presence of relatively high concentrations of certain anti-nutritional factors (Nowacki (I980) cited in Siddhuraju et al., 1995). The anti-nutritional factors of the seeds has been reviewed, Siddhuraju et al. (1995), showing that contents of total free phenolics and tannins in tamarind seem to be higher than in some of the commonly consumed legumes such as chickpea or cowpea (Khan et al. (1979) and Rao \& Deosthale (I982) both cited in Siddhuraju et al., 1995). Since tannins and phenols are water-soluble compounds (Uzogara et al. (1990) cited in Siddhuraju et al., 1995), they can be eliminated by decortication, soaking, heat treatment, or cooking (Singh (1988) cited in Siddhuraju et al., I995). These methods may enhance protein digestibility by reducing the levels of tannins in tamarind seeds. However, tamarind seeds have low levels of phytic acid comparable that of lima bean (Egbe \& Akinyele (1990) cited in Siddhuraju et al., 1995). Phytic acid decreases bio- 
availability of certain minerals and may interfere with the utilization of proteins due to the formation of phytate-protein and phytate-mineral-protein complexes and also inhibits the digestive enzymes (Reddy et al. (1982) cited in Siddhuraju et al., 1995). The phytate could, however, be substantially eliminated by processing methods such as soaking and autoclaving (Reddy et al. (1982) cited in Siddhuraju et al., 1995).

Tamarind seeds contain $2.8 \mathrm{mg} / \mathrm{roo} \mathrm{g}$ cyanogens, which is probably too low to cause any concern since cooking is known to reduce cyanogens content significantly (Sathe \& Salunkhe (1984) cited in Siddhuraju et al., 1995). Trypsin inhibitor activity of tamarind is 26 Trypsin Inhibitor Unit per $\mathrm{mg}$ and exhibits lower inhibitory activity than that of various edible legumes like Cicer arietinum, Lens exculenta, Vigna unguiculata (Al-Bakir et al. (1982) cited in Siddhuraju et al., 1995) or soybean (Kanwar et al. (I991) cited in Siddhuraju et al., I995). In an earlier study with soybeans (Kanwar et al. (I99I) cited in Siddhuraju et al., I995), it was reported that cooking eliminates more than $98 \%$ trypsin inhibitor activity. In vitro protein digestibility of T. indica is $71.6 \%$, which is comparable to the levels reported for Glycine max (Gross (1982) cited in Siddhuraju et al., 1995). This relatively low level of protein digestibility might be attributed to the presence of tannins, phenols and phytic acid.

\section{Leaves and Flowers}

Tamarind flowers and leaves can be eaten as vegetables and are prepared in a variety of dishes (ICRAF, 2007) (Figure 4).The foliage has a high forage value, though tamarind is rarely harvested for this purpose because it affects fruit yields. Tamarind trees growing in woodlands are often eaten by wild animals, such as elephants or giraffes, for which tamarind is a preferred plant, perhaps because of its high crude protein content (El-Siddig et al., 2006). In the southern states of India, cooked seeds of tamarind are occasionally fed to draught animals (ICRAF, 2007).
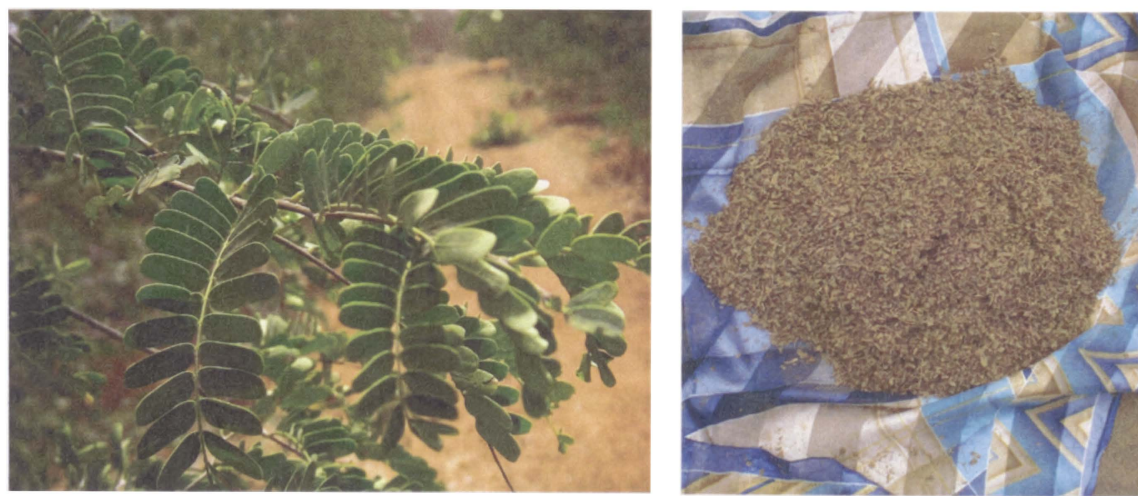

Figure 4. Left: fresh tamarind leaves (Source: Emmy De Caluwé, Senegal, 2007); Right: dried tamarind leaf powder sold at market (Source: Camille De Moor, Mali, 2007). 
Both leaves and bark are rich in tannins. Leaves yield a red dye, which is used to give a yellow tint to cloth previously dyed with indigo (ICRAF, 2007). Tamarind leaves are a fair source of vitamin $C$ and $B$-carotene and the mineral content is high, particularly potassium, phosphorous, calcium and magnesium (El-Siddig et al., 2006).

\section{Chemical and Mineral Composition}

The chemical composition of the dried leaves (Nordeide et al., 1996) (Table XI) shows that the nutritional value is comparable to those of baobab leaves, except amounts of $\mathrm{Ca}$, which in baobab are about five times higher. As reported in Morton (1987), leaves and roots of tamarind contain a number of glycosides such as vitexin, isovitexin, orientin and isoorientin.

\begin{tabular}{l|l} 
Constituent & $g / 100 \mathrm{gdw}$ \\
\hline Dry matter & 96.10 \\
\hline Protein & $\mathrm{I} 4.00$ \\
\hline Fat & 3.90 \\
\hline Carbohydrate & 72.70 \\
\hline Ash & $5 \cdot 50$ \\
\hline & $\mathrm{mg} / 100 \mathrm{~g} \mathrm{dw}$ \\
\hline Ca & 330.00 \\
\hline Fe & $9 \mathrm{I} .00$ \\
\hline Zn & 2.70 \\
\hline Gross energy (kJ/Ioo g dw) & $\mathrm{I} 820.00$ \\
\hline Metabolizable energy (kJ/Ioo g dw) & $\mathrm{I} 600.00$
\end{tabular}

Table XI. Proximate Composition of Dried Tamarind Leaves. Source: Nordeide et al. (1990).

Amino Acids and Vitamins

The amino acid profile of tamarind leaves showed that the leaves of $\mathrm{T}$. indica were potentially acceptable protein sources that would complement the amino acid profile and thus improve the protein quality of local diets (Nordeide et al., 1996). These same authors also report that tamarind leaves only contained traces of $\alpha$ and $B$-carotene. 


\section{Bark}

Tamarind bark and leaves contain tannins. The bark is rich in tannins reaching up to $70 \%$, and as such has found a place for use in the tanning industry. The bark is used for tanning hides and in dyeing (Morton, 1987; El-Siddig et al., 2006). In Zambia, bark tannins are used in the preparation of ink and for fixing dyes (Storss (1995) cited in El-Siddig et al., 2006). The bark is also burnt to make ink in many other African countries. Tamarind twigs are sometimes used as 'chewsticks' whereas the bark is used as a masticatory, alone or as a substitute of lime in betelnut (El-Siddig et al., 2006). The bark yields the alkaloid hordenine (Morton, 1987).

\section{Biological Activity}

\section{Anti-oxidant Activity}

Tamarind seed kernels have a relatively high antioxidant activity and phenolic content (Soong et al., 2004). Four anti-oxidative compounds were isolated and identified from the seed coats: phenolic antioxidants, such as 2-hydroxy-3', 4'-dihydroxyacetophenone, methyl 3,4-dihydroxybenzoate, 3,4-dihydroxyphenyl acetate and epicatechin (Tsuda et al., 2004). These antioxidants may be used for increasing shelf life of food products and improving the stability of lipids and lipid-containing foods by preventing loss of sensory and nutritional quality by preventing lipid peroxidation. These compounds may also find a place as food additives though studies are needed to evaluate their effectiveness within food matrices. Extracts exhibit antioxidant potential by reducing lipid peroxidation in vitro (Tsuda et al., 2004; Tsuda et al. (1993) cited in Sudjaroen et al., 2005). Raw and dry heated tamarind seed coats exhibit good antioxidant activity against the linoleic acid emulsion system and the values were lower and higher than the synthetic antioxidant, butylated-hydroxy-anisole (BHA), and ascorbic acid, respectively (Siddhuraju, 2007).

Phenolic plant compounds may have many biologic effects in terms of health promotion. An important protective effect is reduction of oxidative damage, mediated by lipid peroxidation, which in living systems is strongly associated with mutagenesis, carcinogenesis, ageing, and atherosclerosis (Tsuda et al., 2004; Yagi (I987) and Cultar (I984 and 1992) all cited in Sudjaroen et al., 2005). Pumthong (1999), cited in Sudjaroen et al. (2005), described the antioxidant activity of extracts of tamarind pericarp, and reported the presence of mainly polymeric tannins and oligomeric procyanidins but the latter were not yet identified or quantified.

The anti-oxidative activity of tamarind seed was also investigated by Osawa et al. (1994, cited in El-Siddig et al., 2006). They found that ethanol and ethyl acetate extracts prepared from the seed coat exhibited anti-oxidative activity. This suggests that tamarind seed coats, a by-product of the tamarind gum industry, may have potential as a low cost source of antioxidants (Tsuda et al., 2004), but we note that so many plants and plant extracts show anti-oxidative activity (Ramos et al. (2003) cited in El-Siddig et al., 2006).

Leaf extracts exhibit antioxidant activity in the liver (El-Siddig et al., 2006). Antioxidant activity of tamarind leaves reported by Perez et al. (2003) and Ramos et al. (2003) 
(both cited in Al-Fatimi et al., 2007), was similar to the antioxidant activity of tamarind flowers observed by Al-Fatimi et al. (2007). The latter mechanism is probably caused by polyphenolic compounds which have already been isolated from the seeds (Luengthanaphol et al. (2004) and Sudjaroen et al., (2005) both cited in Al-Fatimi et al., 2007).

Besides anti-oxidant activities, hypolipemic activity was observed from tamarind fruit extract in hypercholesterolemic hamsters (Martinello et al., 2006). Treatment of hypercholesterolemic hamsters with tamarind fruit pulp extract $(5 \%)$ led to a decrease in the levels of serum total cholesterol (50\%), non-high-density lipoprotein cholesterol $(73 \%)$ and triglyceride (60\%), and to an increase of high-density lipoprotein cholesterol levels $(6 \mathrm{r} \%)$. The results of Martinello et al. (2006) indicate the potential of tamarind extracts in diminishing the risk of atherosclerosis development in humans, which is the main contributor for the pathogenesis of myocardial and cerebral infarction.

\section{Anti-inflammatory Activity}

Proteinaceous inhibitors with high inhibitory activities against human neutrophil elastase (HNE) were found in tamarind seeds. A serine proteinase inhibitor, providing high activity against HNE was detected, isolated and purified from tamarind seeds (Fook et al., 2005). Proteinase inhibitors are widely distributed among bacteria, animals and plants. They are present in reproductive and storage organs, and vegetative tissues of most plant families (Ryan (I990) and Shewry \& Lucas (1997) both cited in Fook et al., 2005). They have regulatory and defensive roles, and act as storage proteins (Xavier-Filho (1993) cited in Fook et al., 2005). Among the various groups of proteinase inhibitors, serine proteinase inhibitors are the best studied and have been isolated from various leguminous seeds (Oliveira et al. (2002), Macedo et al. (2002), Mello et al. (2002) and Oliva et al. (2000) all cited in Fook et al., 2005).

Abnormal accumulation of elastase, a serine proteinase from human neutrophil, causes a number of acute and chronic inflammation diseases (Bernstein et al. (1994) cited in Fook et al., 2005). There is a demand for specific and potent exogenous inhibitors of proteinases, such as HNE, associated with these inflammatory processes (Sternlicht \& Werb (1999) cited in Fook et al., 2005). The serine proteinase inhibitor from tamarind seeds needs to be studies to determine whether it could have such application. Anti-inflammatory properties of tamarind fruit pulp were reported (Rimbau et al., 1999).

\section{Anti-microbial Activity}

Tamarind fruits are reported to have anti-fungal and anti-bacterial properties (Ray \& Majumdar (1976), Guerin \& Reveillere (I984), Bibitha et al. (2002), Metwali (2003) and John et al. (2004) all cited in El-Siddig et al., 2006). According to Al-Fatimi and collaborators (2007), in an agar diffusion assay, extracts from $\mathrm{T}$. indica flowers showed antibacterial activity against four bacteria tested (Staphylococcus aureus, Bacillus subtilis, Escherichia coli and Pseudomonas aeruginosa). Antimicrobial activity of T. indica study has been attributed to lupeol (Ali et al. (1998) cited in Al-Fatimi et al., 2007). 
Tamarind leaves possess a strong in vitro antibacterial activity against more then 13 $(8 \mathrm{I} \%)$ common gram positive and gram negative bacteria that were tested (Meléndez \& Capriles, 2006). The latter also reports that tamarind leaf extract was very effective against E. coli. Not much is known, however, about the antibacterial compounds present in the tamarind leaves (Meléndez \& Capriles, 2006) nor the specific compounds responsible for such activity. Tamarind plant extracts have been used to purify drinking water in Burkina Faso and Vietnam (Bleach et al. (199I) cited in El-Siddig et al., 2006).

\section{Anti-fungal Activity}

Tamarind fruits are reported to have anti-fungal as well as anti-bacterial properties (Ray \& Majumdar (1976), Guerin and Reveillere (1984), Bibitha et al. (2002), Metwali (2003) and John et al. (2004) all cited in El-Siddig et al., 2006). Extracts from the fruit appear promising as a potential fungicidal agent against cultures of Aspergillus niger and Candida albicans (El-Siddig et al., I999; El-Siddig et al., 2006).

\section{Anti-viral activity}

Plant extracts of tamarind were reported to have antiviral activity on watermelon mosaic viruses (Chapman (1984) cited in El-Siddig et al., 1999), cow pea mosaic viruses (Singh et al. (1989) cited in El-Siddig et al., 1999) and tobacco mosaic viruses (Stovakova et al. (1994) cited in El-Siddig et al., 1999).

\section{Anti-nematodal}

Tamarind plant extracts were reported to have anti-nematodal activity against Bursaphelenchus xylphilus (Mackeen et al. (1997) cited in El-Siddig et al., 1999).

\section{Moluscicidal Activity}

Extracts from tamarind fruit pulp have shown molluscicidal activity against Bulinus trancatus snails. This is probably due to the presence of saponins in the fruit (Imbabi \& Abu-Al-Futuh (1992a) cited in El-Siddig et al., 2006).

\section{Anti-diabetic Activity}

Frequent research on aqueous extracts of seeds has shown a strong anti-diabetic effect in rats (Maitin et al. (2004) cited in El-Siddig et al., 2006).

\section{Cytotoxic Activity}

Al-Fatimi et al. (2007) reported that methanol extracts of T. indica showed remarkable cytotoxic activity against FL-cells with $\mathrm{IC}_{50}$ values below $50 \mu \mathrm{g} / \mathrm{ml}$. 


\section{Use in Traditional Medicine}

Tamarind is used in herbal medicine in many parts of the world (Siddhuraju, 2007) (Table XII), and medicinal uses of tamarind are uncountable (Morton, 1987). Medicinal uses of tamarind can be found in many cultures and for a wide array of applications (Morton, 1987). The medicinal value of tamarind has been mentioned already in traditional Sanskrit literature (El-Siddig et al., 2006).

Traditionally, tamarind products, leaves, fruits and seeds have been extensively used in traditional Indian and African medicine (Jayaweera (I98I) and Parrotta (I990) both cited in El-Siddig et al., 2006). A number of recent surveys have listed local folk uses of tamarind as remedies for a number of ailments (Rimbau et al. (1999), Sen \& Behera (2000), Punjani \& Kumar (2002), Kristensen \& Lykke (2003), Patil \& Yadav (2003) and Rajendran et al. (2003) all cited in El-Siddig et al., 2006). There is medical interest in the use of purified xyloglucan from tamarind in eye surgery for conjunctival cell adhesion and corneal wound healing (Burgalassi et al. (2000) and Ghelardi et al. (2000) both cited in El-Siddig et al., 2006). Other medicinal interest relates to the use of tamarind fruit to manage fluoride toxicity (Khandare et al. (2000) cited in El-Siddig et al., 2006).

Fruit

Tamarind fruit is regarded as a digestive, carminative, laxative, expectorant and blood tonic (Komutarin et al. (2004) cited in Martinello et al., 2006). Other parts of the plant present antioxidant (Tsuda et al. (1994) cited in Martinello et al., 2006), anti-hepatoxic (Joyeux et al. (I995) cited in Martinello et al., 2006), anti-inflammatory (Rimbau et al. (1999) cited in Martinello et al., 2006), anti-mutagenic (Ramos et al. (2003) cited in Martinello et al., 2006), and anti-diabetic activities (Maiti et al. (2004) cited in Martinello et al., 2006).

Tamarind preparations are universally recognized as refrigerants for fevers, and as laxatives and carminatives. Alone, or in combination with lime juice, honey, milk, dates, spices or camphor, the pulp is considered to be effective as a digestive as a remedy for biliousness and bile disorders, and as an antiscorbutic (Morton, 1987). The laxative properties of the pulp and the diuretic properties of the leaf sap have been confirmed by modern medical science (Bueso (I980) cited in El-Siddig et al., 2006) (Figure 5).
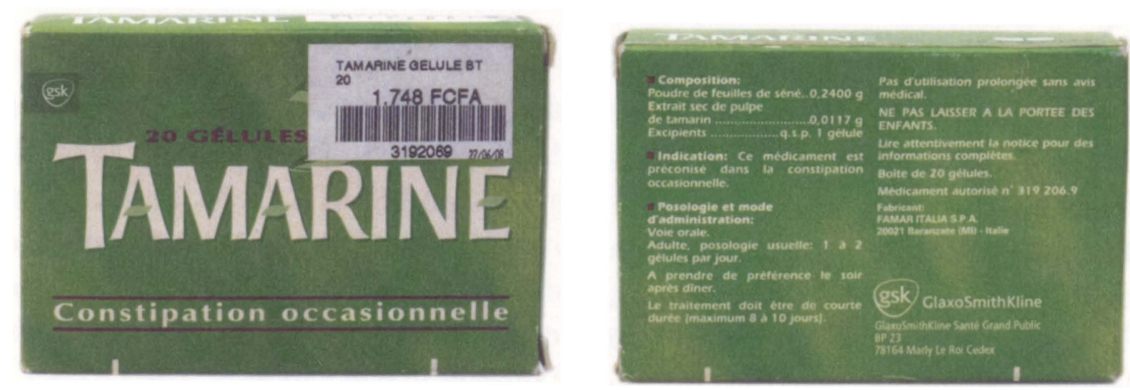

Figure 5. Tamarind used as constipation medicine (Source: Emmy De Caluwé, Senegal, 2007). 
In traditional practice, the pulp is applied on inflammations, is used in a gargle for sore throat and, mixed with salt, as a cream for rheumatism. It is, further, administered to alleviate sunstroke, Datura poisoning, and alcoholic intoxication. In southeast Asia, the fruit is prescribed to counteract the ill effects of overdoses of false chaulmoogra, Hydnocarpus anthelmintica Pierre, given in leprosy. The pulp is said to aid the restoration of sensation in cases of paralysis. In Colombia, an ointment made of tamarind pulp, butter, and other ingredients is used to rid domestic animals of vermin (Morton, 1987).

Tamarind fruits were well-known in Europe for their medicinal properties, having been introduced by Arab traders from India (Rama Rao (1975) cited in El-Siddig et al., 2006). The pulp has been reported in several pharmacopoeias, such as the British and American. Some $90,000 \mathrm{~kg}$ of shelled fruits are annually imported into the United States for the drug trade, primarily from the Lesser Antilles and Mexico. The European supply largely come from Calcutta, Egypt and the Greater Antilles (Morton, 1987).

\section{Seeds}

The powdered seeds are made into a paste for drawing boils and, with or without cumin seeds and palm sugar, are prescribed for chronic diarrhoea and dysentery. The seed coat, too, is astringent, and is also specified for the latter disorders. An infusion of the roots is believed to have curative value in chest complaints and is an ingredient in prescriptions for leprosy (Morton, 1987).

\section{Leaves and Flowers}

Tamarind leaves and flowers, dried or boiled, are used as poultices for swollen joints, sprains and boils. The latter are usually applied after grinding leaves and flowers into powder whereby they are used in lotions or infusions. Lotions and extracts made from them are used in treating conjunctivitis, as antiseptics, as vermifuges, treatments for dysentery, jaundice, erysipelas and haemorrhoids, and various other ailments (Morton, 1987). The leaves, mixed with salt and water, are used to treat throat infections, coughs, fever, intestinal worms, urinary troubles and liver ailments. Leaves and pulp act as a cholagogue, laxative and are often used in treating liver 'congestion', constipation and haemorrhoids (El-Siddig et al., 2006).

\section{Bark}

The bark of the tamarind tree is regarded as an effective astringent, tonic and febrifuge (Morton, 1987; El-Siddig et al., 2006). It is used as a tonic and in lotions or poultices to relieve sores, ulcers, boils and rashes (El-Siddig et al., 2006). Fried with salt and pulverized to an ash, it is given as a remedy for indigestion and colic. A decoction is used in cases of gingivitis, asthma and eye inflammations. Lotions and poultices made from the bark are applied on open sores and caterpillar rashes (Morton, 1987). The bark of the tree should be peeled off if needed for medicinal purposes during the time when the tree is not flowering or when the flowering season ends (El-Siddig et al., 2006). 


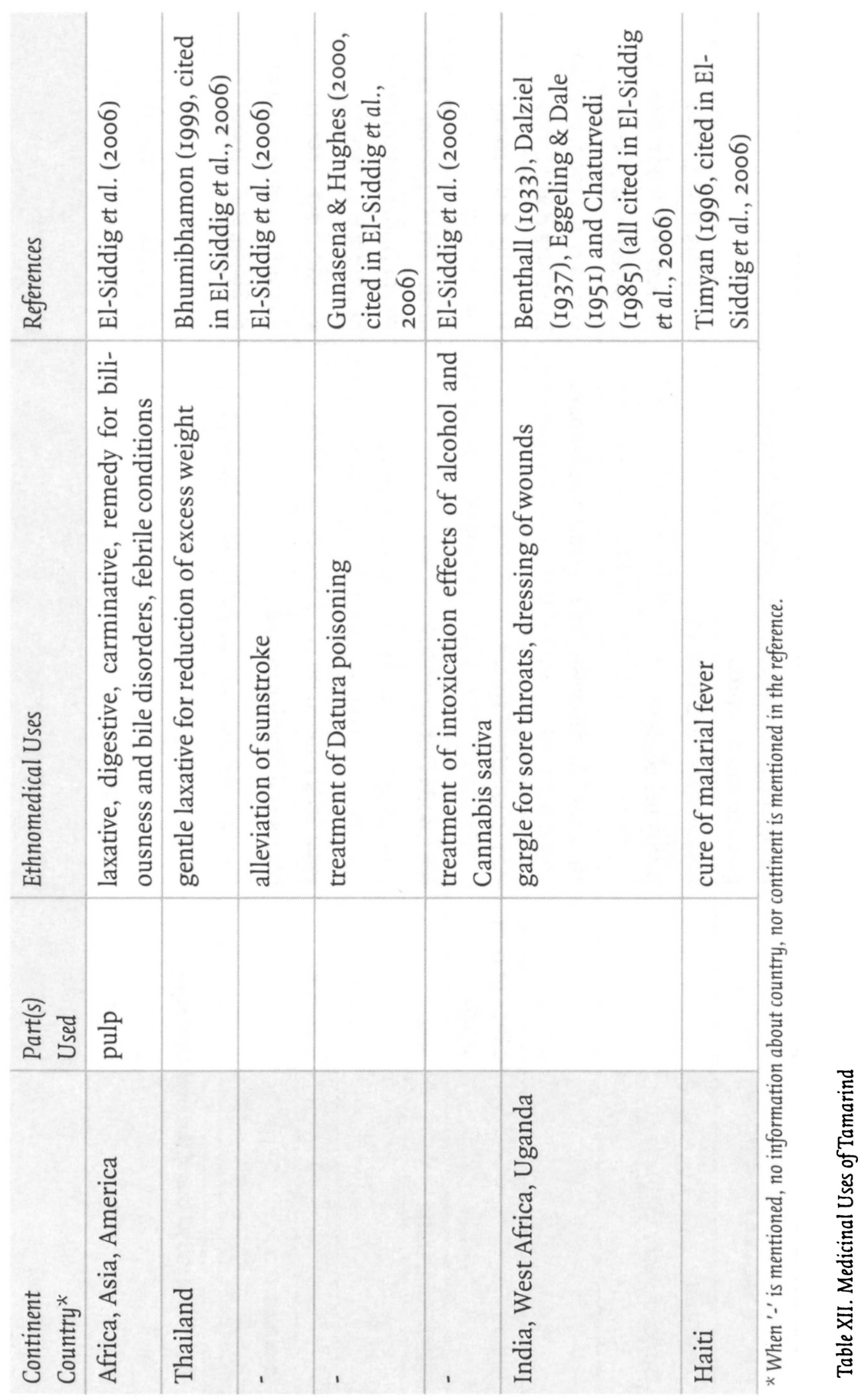




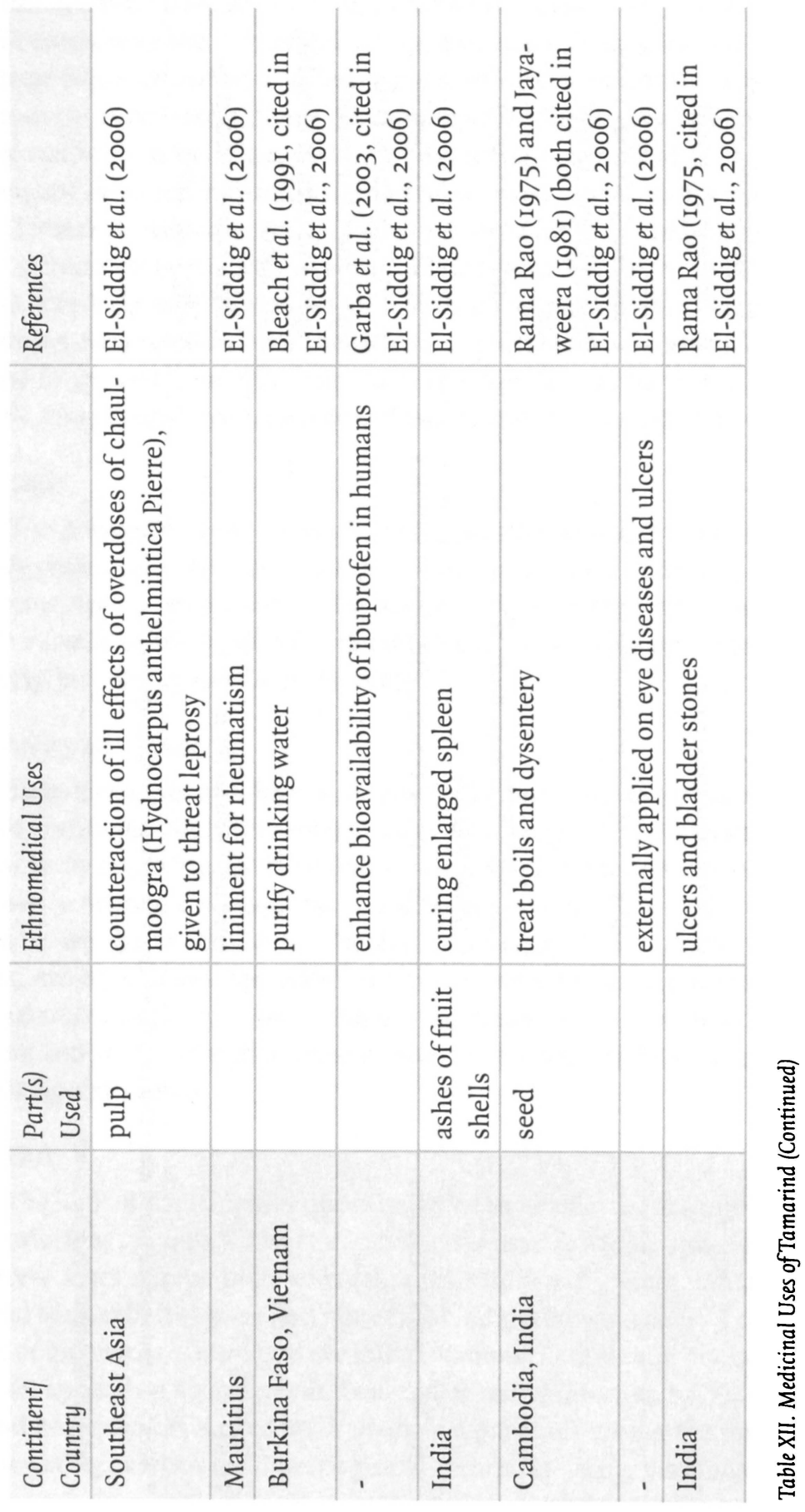




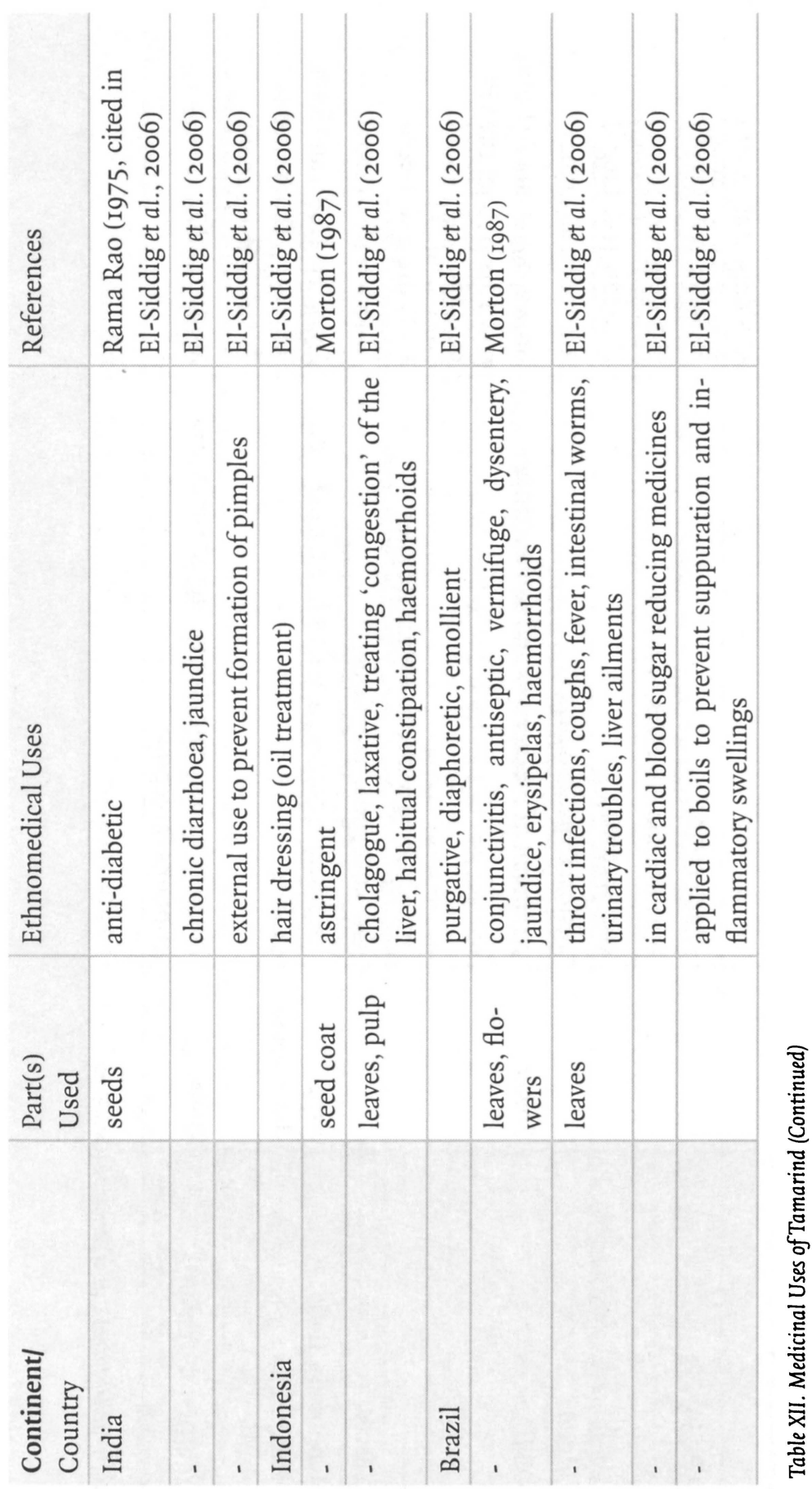




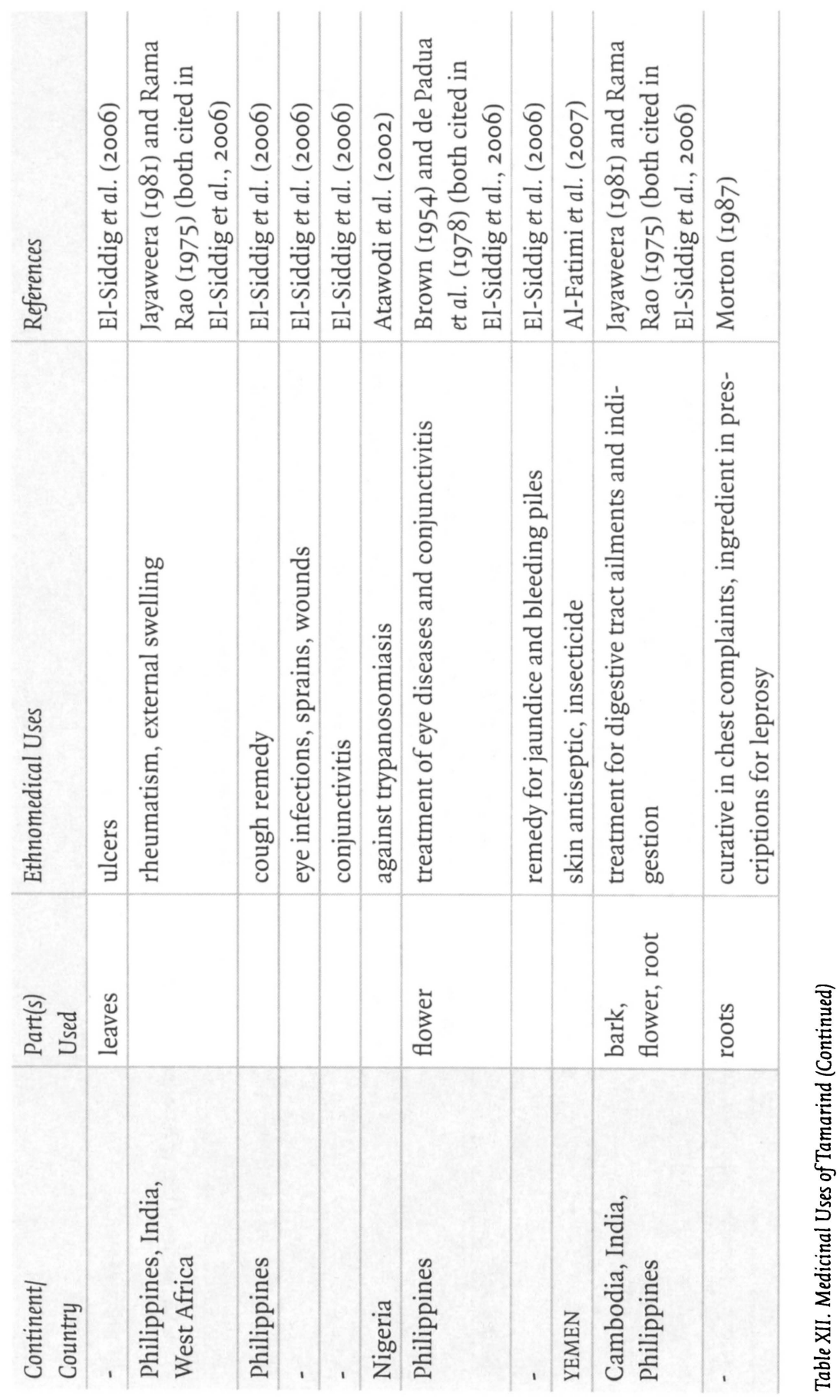




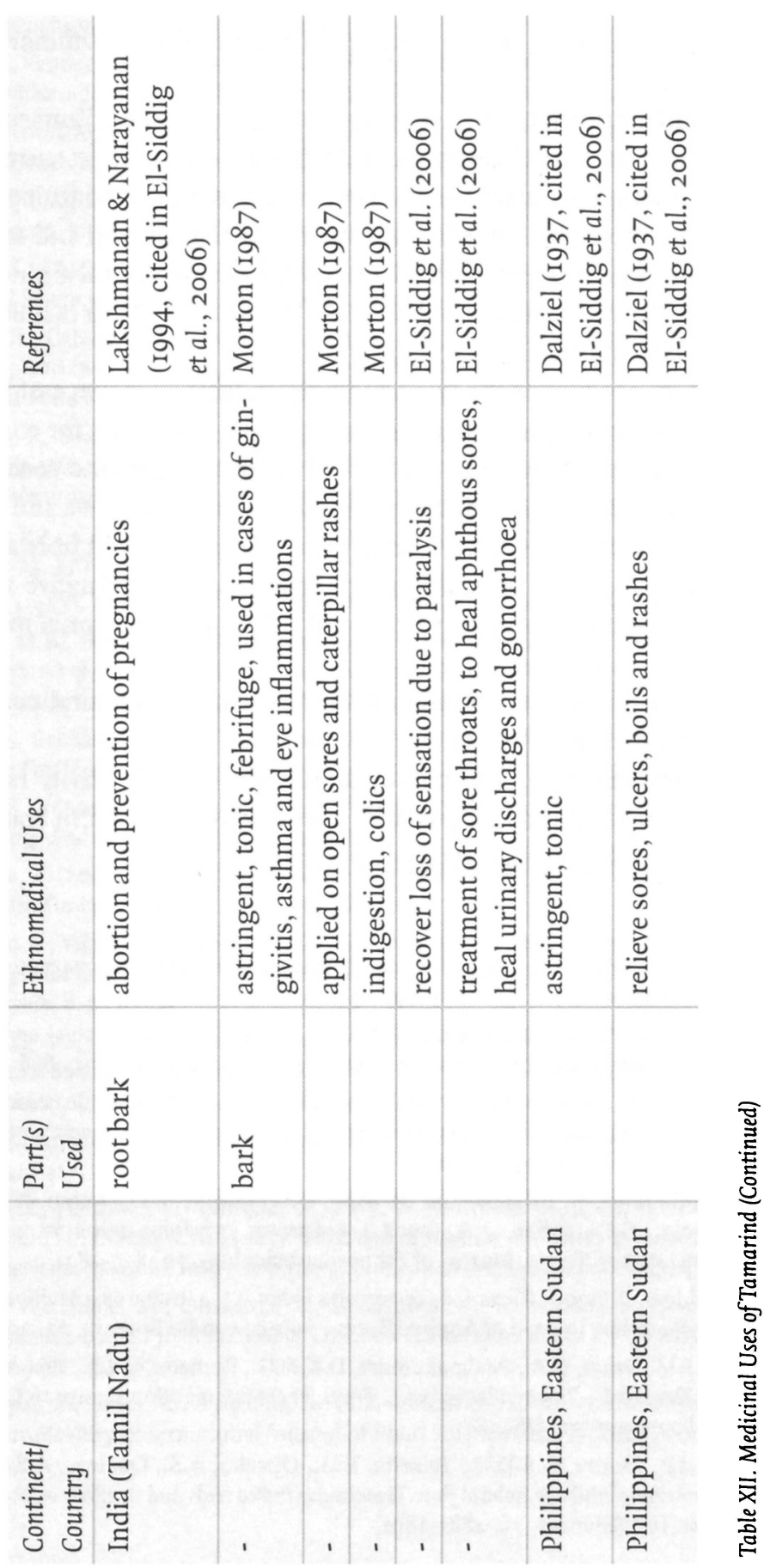




\section{Conclusions}

Virtually every part of Tamarindus indica L. (wood, root, leaves, bark and fruits) has either nutritional or medicinal value, with a number of industrial and commercial applications.

Tamarind is a versatile, nutritious fruit with a great variety of uses. Tamarind fruit pulp is used for seasoning, as a food component, to flavour confections, curries and sauces, and is a main component in juices and certain beverages. Tamarind fruit pulp has a sweet acidic taste due to a combination of high contents of tartaric acid and reducing sugars. The pulp is relatively poor in protein and oil, though rich in several amino acids. It is a good source of $\mathrm{Ca}, \mathrm{P}, \mathrm{Cu}, \mathrm{Mn}$ and $\mathrm{Zn}$, but low in Fe. Vitamin $\mathrm{B}$ content is quite high; carotene and vitamin $\mathrm{C}$ contents are low.

Tamarind seed is a by-product of the tamarind pulp industry. Presence of tannins and other dyeing matters in the seed testa make the whole seed unsuitable for consumption, but they become edible after soaking and boiling in water. Tamarind seed is also used as raw material in the manufacture of polysaccharide (jellose), adhesive and tannin. Seeds and kernels are high in protein content, while the seed coat is rich in fibre and tannins (anti-nutritional factors). Seeds are gaining importance as an alternative source of proteins, and are besides a good source of fatty acids and rich in some essential minerals, such as $\mathrm{Ca}, \mathrm{P}, \mathrm{Mg}$ and $\mathrm{K}$.

Tamarind leaves are a fair source of vitamin $C$ and $B$-carotene; mineral content is high, particularly $\mathrm{P}, \mathrm{K}, \mathrm{Ca}$ and $\mathrm{Mg}$.

Anti-oxidant, anti-inflammatory, anti-microbial and anti-fungal activity has been documented from several plant parts. Tamarind is also extensively used in traditional medicine in many cultures and for a wide array of applications.

\section{References}

Ajayi, I.A., Oderinde, R.A., Kajogbola, D.O., Uponi, J.I. (2006). Oil content and fatty acid composition of some underutilized legumes from Nigeria. Food Chemistry, 99, 115-120.

Al-Fatimi, M., Wurster, M., Schröder, G., Lindequist, U. (2007). Antioxidant, antimicrobial and cytotoxic activities of selected medicinal plants from Yemen. Journal of Ethnopharmacology, III, 657-666.

Almeida, M.M.B., de Sousa, P.H.M., Fonseca, M.L., Magalhães, C.E.C., Lopes, M.dF.G., de Lemos, T.L.G. (2009). Evaluation of macro and micro-mineral content in tropical fruits cultivated in the northeast of Brazil. Ciência e Technologia de Alimentos, 29, 581-586.

Atawodi, S.E., Amed, D.A., Ibrahim, S., Andrew, J.N., Nzelibe, H.C., Onyike, E.O., Anigo, K.M., Abu, E.A., James, D.B., Njoku, G.C., Sallau, A.B. (2002 ). Indigenous knowledge system for treatment of trypanosomiasis in Kaduna state of Nigeria. Journal of Ethnopharmacology, 79, 279-282.

El-Siddig, K., Ebert, G., Lüdders, P. (1999). Tamarind (Tamarindus indica L.): a Review on a Multipurpose Tree with Promising Future in the Sudan. Journal of Applied Botany - Angewandte Botanik, 73, 202-205.

El-Siddig, K., Gunasena, H.P.M., Prasa, B.A., Pushpakumara, D.K.N.G., Ramana, K.V.R., Vijayanand. P., Williams, J.T. (2006). Tamarind - Tamarindus indica L. Fruits for the future 1. Southampton Centre for Underutilized Crops, Southampton, UK, I88p.

Fook, J.M.S.L.L, Macedo, L.LP., Moura, G.E.D.D., Teixeira, F.M., Oliveira, A.S., Queiroz, A.F.S., Sales, M.P. (2005). A serine proteinase inhibitor isolated from Tamarindus indica seeds and its effects on the release of human neutrophil elastase. Life Sciences, 76, 288r-289r. 
Glew, R.H., VanderJagt, D.J., Lockett, C., Grivetti, L.E., Smith, G.C., Pastuszyn, A., Millson, M. (1997). Amino Acid, Fatty Acid, and Mineral Composition of 24 Indigenous Plants of Burkina Faso. Journal of Food Composition and Analysis, 10, 205-217.

Glew, R.S., VanderJagt, D.J., Chuang, L.T., Huang, Y.S., Millson, M., Glew, R.H. (2005). Nutrient content of four edible wild plants from West Africa. Plant Foods for Human Nutrition, 6o, 187-193.

ICRAF - World Agroforestry Centre. ICRAF Agroforestry Tree Database: Tamarindus indica L., URL http:// www.worldagroforestrycentre.org (visited on 31.01.2007).

Ishola, M.M., Agbaji, E.B., Agbaji, A.S. (1990). A Chemical Study of Tamarindus indica (Tsamiya) Fruits Grown in Nigeria. Journal of the Science of Food and Agriculture, 5I, I4I-I43.

Kumar, C.S.; Bhattacharya, S. Tamarind Seed: Properties, Processing and Utilization. Critical Reviews in Food Science and Nutrition. 2008, 48, I-20.

Lockett, C.T., Calvert C.C., Grivetti, L.E. (2000). Energy and micronutrient composition of dietary and medicinal wild plants consumed during drought. Study of rural Fulani, Northeastern Nigeria. International Journal of Food Sciences and Nutrition, 51, 195-208.

Martinello, F., Soares, S.M., Franco, J.J., Santos. A.C, Sugohara., A., Garcia, S.B., Curti, C., Uyemura, S.A. (2006). Hypolipemic and antioxidant activities from Tamarindus indica L. pulp fruit extract in hypercholesterolemic hamsters. Food and Chemical Toxicology, 44, 810-818.

Meléndez, P.A., Capriles, V.A. (2006). Antibacterial properties of tropical plants from Puerto Rico. Phytomedicine, $13,272-276$.

Morton, J. (1987). Tamarind. In: Fruits of warm climates, Morton, J.F. (ed.). Miami, USA, p. II5-I21.

Nordeide, M.B., Harl $\phi y$, A., F $\emptyset$ lling, M., Lied, E., Oshaug, A. (1996). Nutrient composition and nutritional importance of green leaves and wild food resources in an agricultural district, Koutiala, in Southern Mali. International Journal of Food Sciences and Nutrition, 47, 455-468.

Rimbau, V., Cerdan, C., Vila R., Iglesias, J. (1999). Antiinflammatory Activity of Some Extracts from Plants used in the Traditional Medicine of North-African Countries (II). Phytotherapy Research, 13, I28-132.

Saka, J.D.K., Msonthi, J.D. (1994). Nutritional value of edible fruits of indigenous wild trees in Malawi. Forest Ecology and Management, 64, 245-248.

Siddhuraju, P. (2007). Antioxidant activity of polyphenolic compounds extracted from defatted raw and dry heated Tamarindus indica seed coat. LWT, 40, 982-990.

Siddhuraju, P., Vijayakumari, K., Janardhanan, K. (1995). Nutritional and Antinutritional Properties of the Underexploited Legumes Cassia laevigata Willd. and Tamarindus Indica L. Journal of Food Composition and Analysis, 8, 35I-162.

Smith, G.C., Clegg, M.S., Keen, C.L., Grivetti, L.E. (1996). Mineral values of selected plant foods common to southern Burkina Faso and to Niamey, Niger, West Africa. International Journal of Food Sciences and Nutrition, 47, 41-53.

Soong, Y-Y., Barlow, P.J. (2004). Antioxidant activity and phenolic content of selected fruit seeds. Food Chemistry, 88,4 II-4I7.

Sudjaroen, Y., Haubner, R., Würtele, G., Hull, W.E., Erben, G., Spiegelhalder, B., Changbumrung, S., Bartsch, H., Owen, R.W. (2005). Isolation and structure elucidation of phenolic antioxidants from Tamarind (Tamarindus indica L.) seeds and pericarp. Food and Chemical Toxicology, 43, 1673-1682.

Tsuda, T., Watanabe, M., Ohshima, K., Yamamoto, A., Kawakishi, S., Osawa, T. (1994). Antioxidative Components Isolated from the Seed of Tamarind (Tamarindus indica L.). Journal of Agricultural and Food Chemistry, 42, 2671-2674.

Tuntipopipat, S., Zeder, C., Siriprapa, P., Charoenkiatkul, S. (2009). Inhibitory effects of spices and herbs on iron availability. International Journal of Food Sciences and Nutrition, 60, 43-55. 